\title{
Effect of intramuscular administration of dexamethasone on the duration of labor induction
}

\author{
Original Mohammed Abd-Allah Elmaraghy, Tamer El Refaie, Kareem Mohamed Labib, \\ Article \\ Marwa Gamal Mohamed \\ Department of Obstetrics and Gynaecology, Faculty of Medicine - Ain Shams Universityt
}

\begin{abstract}
Introduction: induction of labor is a common obstetric procedure which is performed for a variety of medical and nonmedical indications. If the cervix is unfavorable, prior ripening of the cervix makes induction of labor easier and more successful. There are different methods for ripening of the cervix and making it ready for induction. These methods included medical methods such as the administration of prostaglandins and mechanical methods such as extra amniotic saline infusion, traction on the cervix with Foley catheter and laminaria.

Aim: The aim of the study is to evaluate the efficacy of intramuscular dexamethazone injection prior to induction in improving progression and duration of labour phases.

Subjects and Methods: This study started with 100 Nulliparous Pregnant women who were conducted at the labor wards of Ain-Shams Maternity Hospital. The studied subjects were randomized into two groups ; dexamethasone group (group A) including 50 Nulliparous women $(\mathrm{N}=50)$ and control group (group $\mathrm{B})$ including 50 Nulliparous woman $(\mathrm{N}=50)$.

Results: In this study, the duration of active and second stages decreased without changing the mode of delivery. The study showed no significant statistical differences between the two studied groups regarding fetal heart rate. The duration of second stage in dexamethasone group was shorter than in the control group. Dexamethasone intramuscularly prior to induction significantly shortens duration of normal labor in normal parturient with minimal complications.

Conclusion: An intramuscular injection of dexamethasone before labor induction shortens the duration of labor induction by decreasing the interval between the initiation of induction and the beginning of the active phase, duration of active phase and duration of second stage of labor with no observed maternal or neonatal complications.

Recommendation: Further research with more patients undertaken for the assessment of the effects of the corticosteroids on the duration of labor on the patients with unfavorable cervix as well as maternal and perinatal morbidity and mortality rate.
\end{abstract}

Key Words: dexamethasone injection, Duration of labour phases.

Received: 16 August 2018, Accepted: 10 October 2018

Corresponding Author: Marwa Gamal Mohamed, Department of Obstetrics and Gynaecology, Faculty of Medicine, Ain Shams University, Tel: +20 1099543064, E-mail: marwa_prof_med@yahoo.com

ISSN: 2090-7265, November 2018, Vol.8, No. 4

\section{INTRODUCTION}

Induction of labor is a common obstetric procedure which is performed for a variety of medical and nonmedical indications ${ }^{[1]}$.

If the cervix is unfavorable, prior ripening of the cervix makes induction of labour easier and more successful. There are different methods for ripening of the cervix and making it ready for induction. These methods included medical methods such as the administration of prostaglandins and mechanical methods such as extra amniotic saline infusion (EASI), traction on the cervix with Foley catheter and laminaria. One of the methods proposed for the speeding up of the labour process (labour induction) is the use of corticosteroids ${ }^{[2]}$. We use in our study medical induction via oxytocin; but prior to it we use intramuscular dexamethasone to potentiate the effect.

The process of childbirth starts from the axis of the hypothalamus, the pituitary gland and the uterus. Other axes share in this process like adrenal gland steroid hormones. Steroid substances produced in the adrenal glands of the human fetus affect the placenta and the membranes and transform the myometrium from the static to the contractile state. The placenta may play a role in this process because it produces a lot of corticotropin-releasing hormone. The adrenal glands of the fetus do not produce a considerable amount of cortisol until the third trimester. During the last weeks of pregnancy, the cortisol and dehydroepiandrosterone sulfate contents of the fetus rise. 
Placental corticotropin-releasing hormone is not under the influence of negative feedback from cortisol ${ }^{[3]}$.

The concentration of corticotropin-releasing hormone in the fetus rises during the last 12 weeks of pregnancy. This results in modification of the contractility of the uterus, stimulation of the membranes to produce more prostaglandins, stimulation to produce corticosteroids from placental adrenaline and increase in the estrogen content. This will disturb the ratio of estrogen to progesterone and will cause expression of contractile proteins. In fact, the increase in corticotropin-releasing hormone near the end of pregnancy confirms the presence of a placental-fetal $\operatorname{clock}^{[3]}$.

One of the methods proposed for the strengthening and speeding up of the labor process (labor induction) is using corticosteroids, although the effects of using these substances in the labor process is not well understood studies conducted on animals indicate the importance of the secretion of cortisol by adrenal glands in sheep fetuses and in fetuses of other animals on starting labor. Moreover, it has been observed that infusion of glucocorticoids into sheep fetuses causes premature birth induction. These studies have prepared the way for bringing up the role of corticosteroids in the speeding up of labor induction in women. In studies carried out, corticosteroids have been employed using extra-amniotic and intravenous methods and in some of these studies, both methods have proved successful ${ }^{[4]}$.

However, in reviews, conflicting results have been obtained in this regard. In one of these reviews, it was shown that congenital hyperplasia of the fetus resulting from disturbances in cortisol production causes post- term births. In some studies, an association has been observed between stress in the mother and premature childbirth ${ }^{[5]}$.

In this research, we will study the role played by intramuscular dexamethasone in the process of labor progression and on the duration of active phase and other labor phases.

\section{AIM OF THE WORK}

The aim of the study is to evaluate the efficacy of intramuscular dexamethazone injection prior to induction in improving progression and duration of labour phases.

\section{SUBJECTS AND METHODS}

Study design: Double blinded randomized, controlled trial.

Study setting: at labor ward of Ain-Shams University Maternity Hospitals.

Study period: The study population included a total number of 100 women who fulfilled the inclusion criteria of the study within the time of the study. The study was approved by the Ethics Board of Ain-Shams University and an informed written consent was taken from each participant in the study.

\section{Our Inclusion criteria:}

1. Gestational age (3842-) weeks according to a reliable date for the last menstrual period and a first-trimester ultrasound evaluation.

2. Vertex presentation.

3. Singleton fetus.

4. Favorable cervix with a Bishop score of 7 or greater.

5. Intact fetal membranes.

6. No contra indication for vaginal delivery.

\section{Our Exclusion criteria:}

1. Indication for cesarean section e. g. Placenta previa, intrauterine growth retardation, non-vertex presentation and previous cesarean section.

2. Maternal medical disorders as diabetes mellitus and severe pre-eclampsia.

3. Preterm labor and premature rupture of membranes.

4. Significant vaginal bleeding. Placenta previa, probable placental abruption.

5. Fetal macrosomia $>3.5 \mathrm{~kg}$ (estimated by $\mathrm{u} / \mathrm{s})$.

6. Poor Bishop score.

\section{Blinding}

Blinding of the study procedures was possible, because the nature of the two selected injection cannot be distinct. Pregnant women were randomized (assigned) either to receive dexamethasone sodium phosphate $8 \mathrm{mg}(2 \mathrm{~mL})$ or $(2 \mathrm{~mL})$ distilled water. The first vaginal examination and determination of the Bishop score was performed by the investigator and the injection of dexamethasone or distilled water was performed by his coworker; thus, neither the participants nor the investigator knew the nature of the injection

\section{Randomization and allocation with concealment:}

Women who fulfilled the inclusion criteria was given numerical name (code) from 1001 to 1100 sheeted on graph. 
Then codes were selected randomly through randomization computerized program. Then each collection of codes was grouped into two groups; group A and $\mathrm{B}$ according to type of saline which is coded by A and $\mathrm{B}$ with blinding so our tables was as follow;

Study groups: Women who fulfil the inclusion criteria and were allocated to the groups through randomization by Recruitment.

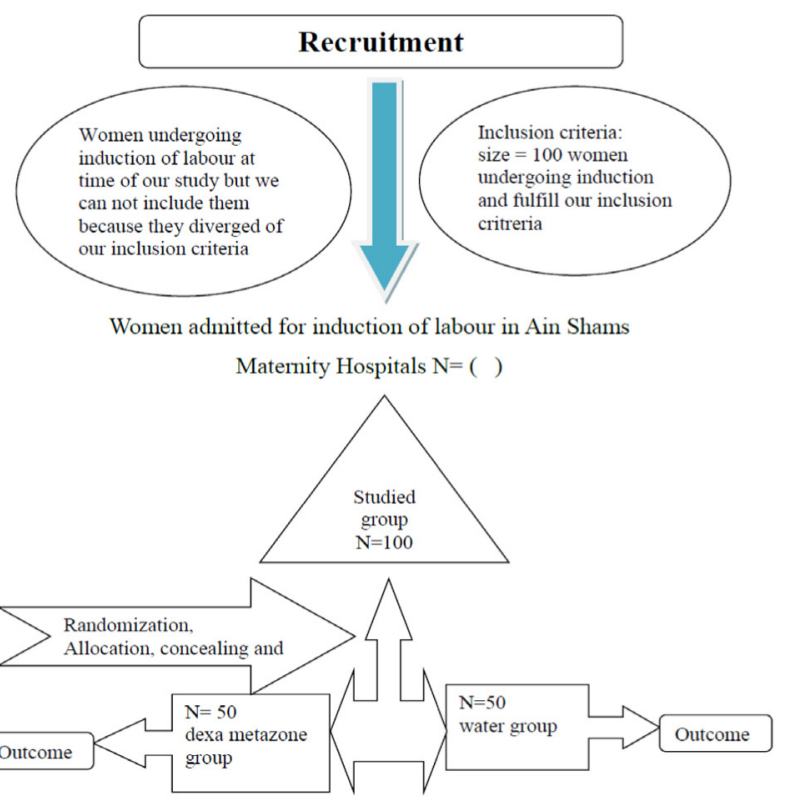

Group $A$ (Dexamethasone group) $n=50$ : Eight $\mathrm{mg}$ $(2 \mathrm{ml})$ of the product dexamethasone sodium phosphate was administrated intramuscularly at least half an hour and maximally 6 hours before initiation of labor induction. Moreover, labor induction was performed by standard protocol, i. e, started by 5 drops /minute of $500 \mathrm{cc}$ saline + 5 units of oxytocin with the dose increased by 510- drops / minute every 30 minute till optimal contractions are reached (3uterine contractions in 10 minutes and lasting for 4050- seconds each).

Group B (Control group) $\boldsymbol{n}=50:(2 \mathrm{ml})$ of distilled water was administrated intramuscularly at least half an hour and maximally 6 hours before initiation of labor induction; and labor induction was performed by the same protocol as above.

The interval between initiation of induction and beginning of the active phase of labor (cervical dilatation of 3-4 cm plus 3 forceful contractions over a 10-minute span), the duration of active phase and the duration of $2^{\text {nd }}$ and $3^{\text {rd }}$ stages of labor were compared between the two groups.

\section{Every subject was subjected to:}

1. Verbal consent

2. Complete history to exclude systemic disorders, congenital fetal malformation and contraindications for vaginal delivery.

3. General examination of the patients including pulse, blood pressure and body mass index, [weight (kg)/ height (m2)] (20-25) normal weight, (25-30) overweight, (30-35) obese, (35-40) very obese and $>40$ morbid obese.

4. Abdominal examination including presentation, station of fetal head, fetal heart rate, uterine contractions and exclusion of multiple pregnancies.

5. Local examination to determine cervical dilatation at the beginning of intervention, presenting part, station of fetal head, pelvis adequacy and Bishop scoring.

6. Partographic representation of labor.

7. Sonographic examination including assessment of fetal well being by biophysical profile.

8. Determination of:

i. The interval between initiation of induction and beginning of the active phase of labor.

j. Duration of active phase of labor (starting with cervical dilatation of 3-4 $\mathrm{cm}$ up to full cervical dilatation).

k. Duration of $2^{\text {nd }}$ stage of labor defined as (period of time from full cervical dilatation until delivery of the fetus).

1. Duration of 3rd stage.

\section{Principles:}

\section{1-Assessment of labor process was done by a partograph:}

A partograph is a graphical record of progress during labor.

Progress is measured by cervical dilation against time in hours and a record is made of the important conditions of the mother and fetus that may arise during labor process. The partograph was developed and extensively tested by the WHO. 


\section{Components of the partograph:}

Part I: Assessment of the fetal condition.

Part II: Progress of labor.

Part III: Assessment of the maternal condition.

Part IV: Outcome of labour.

\section{2-Justification upon condition of the cervix or favorability} was done by Bishop scoring system.

Elements of Bishop Score were; station of the presenting part, dilatation, consistency, effacement and position of the cervix $^{(6)}$.

\section{The primary outcome measures include}

a. Duration between initiations of induction till active phase of labor is reached.

b. The duration of $1^{\text {st }}$ stage, $2^{\text {nd }}$ stage and $3^{\text {rd }}$ stage of labour.

\section{The secondary outcome measures include:}

Mode of delivery:

Participants with diabetes, preeclampsia, underlying diseases, breech, macrosomia, twins, women with spontaneous rupture of the amniotic sac and patients who refused to take part in the study was omitted.
We use checklists in the study to collect and record data. When these 100 patients was admitted to the maternity ward, the person in charge of the study examine them and determine their Bishop Score. Every other one of these women was then intramuscularly injected with either 8 milligrams of dexamethasone or 8 milliliters of distilled water.

The dexamethasone and distilled water was provided for the person in charge of the study in syringes marked with A or B. This person was not aware of the contents of these syringes for the duration of the study. The patients was reexamined four hours after the injections to determine their Bishop Score and oxytocin was used for labor induction. The related information was stored in checklists A and B.

Finally, the patients was examined with respect to improvements in the condition of their crevices during the average periods extending from the start of induction to the beginning of the active stage and from the start of the active stage to the beginning of the second stage of childbirth and the third stage.. Using the statistical software SPSS - 16, this information was entered into a computer, the frequencies, means and standard deviations was calculated. The obtained results were analyzed by employing the student's t-test and Chi-square test at $\mathrm{P}<0$. 05 .

The procedure used in conducting the study was thoroughly explained to the patients, and if any problem arose for any of the patients, they would be omitted from the study. The patients were given written informed consent forms and they participated in the study voluntarily.

Table 2: Represent sum of results given by $t$ test of both groups A and B

\begin{tabular}{|c|c|c|c|c|c|c|}
\hline & \multicolumn{2}{|c|}{ MEAN } & \multicolumn{2}{|c|}{ S.D } & \multirow{2}{*}{ Difference value } & \multirow{2}{*}{$\mathrm{P}$ value } \\
\hline & A GROUP & B GROUP & A GROUP & B GROUP & & \\
\hline Sys. B.P diast. & $108.3 \backslash 77.9$ & $110.2 \backslash 74.4$ & $+-7.64 \backslash 7.43$ & $+-7.7 \backslash 8.8$ & $-1.258 \backslash 2.149^{*}$ & $0.105 .017^{*}$ \\
\hline Before active & 3.92 & 6.24 & 0.785 & 1.384 & $10.3 * *$ & $<.00001 * *$ \\
\hline $1^{\text {st }}$ stage & $3.38 \mathrm{hr}$. & 6.24 & 1.16 & 1.384 & $11.2 * *$ & $<.00001$ \\
\hline $2^{\text {nd }}$ stage & $41.2 \mathrm{~m}$ & $65 \mathrm{~m}$ & 36.3 & 35.66 & $3.3^{*}$ & $.0013 *$ \\
\hline $3^{\text {rd }}$ stage & $7.88 \mathrm{~m}$ & $25.4 \mathrm{~m}$ & 6.81 & 8.259 & $11.6^{* *}$ & $<.001 * *$ \\
\hline Fetal pulse & 122 & 121 & 13.3 & 6.8 & 0.9 & 0.18 \\
\hline B.M.I & 23.76 & 24.3 & 2.68 & 4.12 & 0.725 & 0.235 \\
\hline
\end{tabular}

Note: * means this is significant value

** means highly significant value 
It was explained to the patients that prescription of dexamethasone does not increase the risk they were exposed to. Also, the useful effects of this drug had not been proved yet, so, its prescribing would not be ethically wrong.

\section{RESULTS}

This study started with 100 Nulliparous pregnant women who were conducted at the labor wards of Ainshams Maternity Hospital. The studied patients were randomized into two groups: Dexamethasone group (group A): This group included 50 Nulliparous women $(\mathrm{N}=50)$. Control group (group $\mathrm{B}$ ): This group included 50 Nulliparous woman $(\mathrm{N}=50)$. Data were collected in a specific record forms and the results were tabulated and statistically analyzed as shown below.

Table (1) showed significant difference between diastolic blood pressure and no difference in systolic. Table (2) shows high significant difference in time taken for each phase in each group. There was no significant difference of fetal pulse between both groups as shown in Table (3). Table of t-test shows no difference between both groups and according to BMI, no significant difference between the two groups table (4)

Table 1: Bishop Scoring System Used for Assessment of Inducibility ${ }^{(7)}$.

\begin{tabular}{cccccc}
\hline \multicolumn{5}{c}{ Factor } \\
\hline Score & $\begin{array}{c}\text { Dilatation } \\
(\mathrm{cm})\end{array}$ & $\begin{array}{c}\text { Effacement } \\
(\text { Percent })\end{array}$ & $\begin{array}{c}\text { Station } \\
(-3 \text { to }+2)\end{array}$ & $\begin{array}{c}\text { Cervical } \\
\text { Consistency }\end{array}$ & $\begin{array}{c}\text { Cervical } \\
\text { Position }\end{array}$ \\
\hline 0 & Closed & $0-30$ & -3 & Firm & Posterior \\
1 & $1-2$ & $40-50$ & -2 & Medium & Midposition \\
2 & $3-4$ & $60-70$ & -1 & Soft & Anterior \\
3 & $\geq 5$ & $\geq 80$ & $+1,+2$ & - & - \\
\hline
\end{tabular}

Table 3: Sub-table for comparison between group A taking Dexa and group B who did take placebo

\begin{tabular}{ccccccc}
\hline & \multicolumn{2}{c}{ MEAN } & \multicolumn{2}{c}{ S.D } & P & Significant \\
\cline { 2 - 5 } & $\begin{array}{c}\text { A } \\
\text { GROUP }\end{array}$ & $\begin{array}{c}\text { B } \\
\text { GROUP }\end{array}$ & $\begin{array}{c}\text { A } \\
\text { GROUP }\end{array}$ & $\begin{array}{c}\text { B } \\
\text { GROUP }\end{array}$ & & \\
\hline $\begin{array}{c}\text { Sys. } \\
\text { B.P }\end{array}$ & 108.3 & 110.2 & +-7.64 & +-7.7 & 0.105 & Not \\
diast. & 177.9 & 174.4 & 17.43 & 18.8 & $.017 *$ & sign \\
\hline
\end{tabular}

Table 4: Sub-table of t-test shows difference between group A taking Dexa A and group B who did not take

\begin{tabular}{cccccc}
\hline & \multicolumn{2}{c}{ MEAN } & \multicolumn{2}{c}{ S.D } & \multirow{2}{*}{ P value } \\
\cline { 2 - 5 } & $\begin{array}{c}\text { A } \\
\text { GROUP }\end{array}$ & $\begin{array}{c}\text { B } \\
\text { GROUP }\end{array}$ & $\begin{array}{c}\text { A } \\
\text { GROUP }\end{array}$ & $\begin{array}{c}\text { B } \\
\text { GROUP }\end{array}$ & \\
\hline Before active & 3.92 & 6.24 & 0.785 & 1.384 & $<.00001^{* *}$ \\
$1^{\text {st }}$ stage & $3.38 \mathrm{hr}$. & 6.24 & 1.16 & 1.384 & $<.00001$ \\
$2^{\text {nd }}$ stage & $41.2 \mathrm{~m}$. & $65 \mathrm{~m}$. & 36.3 & 35.66 & $.0013^{*}$ \\
$3^{\text {rd }}$ stage & $7.88 \mathrm{~m}$. & $25.4 \mathrm{~m}$. & 6.81 & 8.259 & $<.001^{* *}$ \\
\hline
\end{tabular}

Table 5: Sub-table of t-test of 2 groups; group A taking Dexa and group B who did not

\begin{tabular}{cccccc}
\hline & \multicolumn{2}{c}{ MEAN } & \multicolumn{2}{c}{ S.D } & \\
\cline { 2 - 5 } & $\begin{array}{c}\mathrm{A} \\
\text { GROUP }\end{array}$ & $\begin{array}{c}\mathrm{B} \\
\text { GROUP }\end{array}$ & $\begin{array}{c}\mathrm{A} \\
\text { GROUP }\end{array}$ & $\begin{array}{c}\mathrm{B} \\
\text { GROUP }\end{array}$ & \\
\hline Fetal pulse & 122 & 121 & 13.3 & 6.8 & 0.18 \\
\hline
\end{tabular}

Table (6): Table of t-test shows no difference between both groups according to BMI.

\begin{tabular}{cccccc}
\hline & \multicolumn{2}{c}{ MEAN } & \multicolumn{2}{c}{ S.D } & \\
\cline { 2 - 5 } & A & B & A & B & P value \\
& GROUP & GROUP & GROUP & GROUP & \\
\hline B. M. I & 23.76 & 24.3 & 2.68 & 4.12 & 0.235 \\
\hline
\end{tabular}

\section{DISCUSSION}

In humans, the placenta synthesizes $\mathrm{CRH}$ and the exponential rise of this hormone in maternal plasma correlates with the timing of birth ${ }^{[8]}$. Recently, CRH has been shown to stimulate placental production of estrogens and to inhibit placental synthesis of Progesterone ${ }^{[9]}$. The increase in the maternal estrogen to progesterone ratio may promote the expression of contraction-associated proteins in the myometrium, thus facilitating the initiation of parturition ${ }^{[10]}$. Also, glucocorticoids induce the production of $\mathrm{CRH}$ by the placenta and the production of prostaglandins (PGF2 and PGE2) by the fetal membrane in humans ${ }^{[11]}$.

Therefore, glucocorticoids also play an important role in human parturition. This double blind randomized controlled trial was conducted in the labor ward of Ain-Shams University Hospital to evaluate the effect of intramuscular dexamethasone administration on the duration of labor induction. In the present study, the duration of labor induction was shortened as the interval between beginning of labor induction and beginning of active phase and the duration of active phase of labor were decreased. These finding are in agreement with those of Elliott et al. ${ }^{[12]}$ who maturation in triplet and quadruplet births is associated with the increase of uterine contractions and preterm labor with cervical changes requiring tocolysis. This also goes with those of Ziaei et al. ${ }^{[13]}$ who performed a randomized controlled study conducted on 66 women with gestational age of 41 weeks and over and favorable cervix (bishop score $>$ or $=7)$. The study group $(\mathrm{n}=33)$ received $10 \mathrm{mg}$ of dexamethasone phosphate intramuscularly in two doses at an interval of 12 hours, and the day after the enrolling administration intravenous oxytocin was given. The control group $(n=33)$ received only intravenous oxytocin 24 hours after enrolling. The number of patients to enter the active phase of labor was significantly higher in the study group than in the control group $(\mathrm{n}=33[100 \%]$ vs $\mathrm{n}$ $=29[87.9 \%], \mathrm{p}<0.039)$. The mean time interval between 
induction of labor and the active phase was significantly shorter in the study group than in the control group (1.7 $+/-1.5$ hours vs $4+/-1.7, \mathrm{P}<0.0001)$. They concluded that induction of labor with the use of intramuscularly injected dexamethasone phosphate reduced the time interval between the induction of labor and the active phase. In this study, the duration of second stage in dexamethasone group was shorter than in the control group. Moreover in agreement with Kashanian et al. ${ }^{[14]}$ who carried out a double-blind, randomized, controlled trial upon 122 nulliparous with a full-term pregnancy and a Bishop score of 7 or greater and randomly assigned to receive a single $8 \mathrm{mg}$ dose of dexamethasone or placebo 6 hours before initiation of labor induction, the interval between initiation of labor induction and beginning of active phase of labor was shorter in the dexamethasone group than in the control group (3. $09 \pm 1.5$ hours vs. $4.21 \pm 1.8$ hours; $\rho=0.001$ ). The duration of the second stage of labor was also shorter in the dexamethasone group (22. $23 \pm 16.09$ minutes vs. 29. $01 \pm 15.32$ minutes; $\rho=0$. 014). They concluded that the administration of dexamethasone was found to shorten the duration of labor induction.

In this study, the duration of active and second stages was decreased without change on mode of delivery. In agreement with Barkai et al. ${ }^{[15]}$ whose purpose was to examine the hypothesis that corticosteroids, when administered extra-amniotically, can enhance the labor process and reduce the induction-to-delivery interval. A double-blind randomized study was conducted on 98 women with gestational age of 36 to 42 weeks, an unfavorable cervix and medical indications for delivery; they were assigned to receive either $20 \mathrm{mg}$ of dexamethasone in saline solution $(n=50)$ or saline solution only $(n=48)$ administered extra-amniotically through an intracervical inflated Foley balloon catheter. The mean time intervals between induction of labor to the active phase and between induction of labor to delivery were significantly shorter in the study group compared with those of the control group $(7.8+/-3.1$ hours vs $9.9+/-3.9$ hours, $p<0.03,11.9+/-3.0$ hours vs $14.5+/-4.8$ hours, $\mathrm{p}<0.01$, respectively). Those not receiving steroids were at a 3.2 higher risk of having a longer time interval of induction to delivery. The general success rate in achieving vaginal delivery was, however, similar between the two groups. They concluded that induction of labor with the use of an intracervical Foley balloon catheter and extra-amniotic corticosteroids reduces the time interval from induction of labor to delivery. This was in agreement with Kashanian et al. ${ }^{(16)}$ who performed a double blind randomized controlled study on 84 pregnant women with gestational age of $40 \mathrm{w}$ or more and a bishop score $<5$. In 41 patient $(20 \mathrm{mg})$, dexamethasone plus extraamniotic saline infusion (EASI) was prescribed and in 43 patients (EASI) alone. Oxytocin was started after 6 hours. A comparison between extra-amniotic normal saline solution infusion alone and in combination with dexamethasone for ripening of cervix and induction of labor was done. There were statistically significance differences between the two groups as regards the duration between oxytocin infusions till delivery which were $7.25 \pm 2$. $86 \mathrm{~h}$ in dexamethasone group versus $9.76 \pm 3.91 \mathrm{~h}$ in B group. Also, there were no significant differences between the two groups according to caesarean section rate. They concluded that adding dexamethasone to extra-amniotic saline solution infusion can shorten the duration of labor induction. On the contrary Word et al. ${ }^{(17)}$ compared the effects of corticosteroids for third trimester cervical ripening or induction of labour with other methods of cervical priming or induction of labour and found that there is no benefit of intramuscular administration of corticosteroids with intravenous oxytocin when compared with oxytocin alone. They performed their study upon small number of patients as 66 women were included. The primary outcome vaginal birth within 24 hours was not reported.

In this study, there were no significant statistical differences between the two studied groups as regards fetal heart rate. This was in agreement with Kashanian et al. ${ }^{(14)}$ who found that there were no significant differences in fetal heart rate. It seems clear that corticosteroids administered intramuscularly could facilitate the induction and the delivery process in extended pregnancy. This can reduce prolonged pregnancy rates and the related complications. These drugs can facilitate the initiation of labor and shorten the time interval between the induction of labor with oxytocin and the active phase. The side effects of glucocorticoid (e. g. leukocytosis, immunosuppression and increased glucose) are of minimal importance, unless in diabetic pregnancies or premature rupture of the membranes, which were excluded from this study. It is suggested that further research with more patients would be undertaken for the assessment of maternal and perinatal morbidity and mortality rate as well as the effects of the corticosteroids on the patients with unfavorable cervix table (5\&6).

\section{CONCLUSION}

In conclusion, an intramuscular injection of dexamethasone before labor induction is found to shorten the duration of labor induction by decreasing the interval between the initiation of induction and the beginning of the active phase, duration of active phase and duration of second stage of labor with no observed maternal or neonatal complications.

\section{RECOMMENDATION}

Further research with more patients is undertaken for the assessment of the effects of the corticosteroids on the duration of labor on the patients with unfavorable cervix as well as maternal and perinatal morbidity and mortality rate. 


\section{REFERENCES}

1. Schwartz RH and Jones RW (2016): Trans- placental hyponatremia due to oxytocin. Br. Med. J., 1: 152-153.

2. Kavanagh J, Kelly AJ and Thomas J (2006): Corticosteroids for cervical ripening and induction of labor. Cochrane Database Syst. Rev., (2): CD003100.

3. ACOG Practice Bulletin No. 107 (2009): Induction of labor. Obstet. Gynecol., 114 (2 Pt 1): 386.

4. James A. (2012): Postterm Pregnancy; NMS Obstetrics and Gynecology [editor; Pfeifer SM], Lippincott Williams and Wilkins, 7th edition.

5. Batista M, Reyes R, Santana M, et al. (2011): Induction of parturition with aglepristone in the Majorera goat. Reprod Domest Anim., 46 (5): 882-888.

6. Bishop EH.(1964): Pelvic scoring for elective induction. Obstet. Gynecol., 24:266-8. PMID: 14199536

7. Cunningham FG, Gant NF Leveno KJ, et al. (2010): Induction of labor; Williams Obstetrics [editors; Cunningham FG, Gant NF, Leveno KJ, Gilstrap LC Ш, Hauth JC, Wenstrom KD] New York: MC Graw hill, 23rd edition, Chapter 22

8. McLean M, Bisits A, Davies J, et al. (1995): A placental clock controlling the length of human pregnancy. Nature Medicine., 1: 460.

9. Yang R, You X, Tang X, et al. (2006): Corticotropinreleasing hormone inhibits progesterone production in cultured human placental trophoblasts. J. Mol. Endocrinol., 37: 533.

10. Mastorakos G and Ilias I (2003): Maternal and fetal hypothalamic- pituitary-adrenal axis during pregnancy and postpartum. Ann. NY. Acad. Sci., 997: 136.
11. Cheng YH, Nicholson Rc, King B, et al. (2000): Glucocorticoid stimulation of corticotropin-releasing hormone gene expression requires a cyclic adenosine 3959-monophosphate regulatory element in human primary placental cytotrophoblast cells. J. Clin. Endocrinol. Metab., 85: 1937.

12. Elliott JP and TG Radin (1995): The effect of corticosteroid administration on uterine activity and preterm labour in high order multiple gestations. Obstet. Gynecol., 85: 250.

13. Ziaei S, Rosebehani N, Kazeminejad A, et al (2003): The effects of intramuscular administration of corticosteroids on the induction of parturition. J. Perinat. Med., 31(2): 134-139.

14. Kashanian M, Dadkhah F and Mokhtari F (2008): Effect of intramuscular administration of dexamethasone on the duration of labor. Int. J. Gyn. Obs., 102 (3):259262 .

15. Barkai G, Cohen SB, Kees S, et al. (1997): Induction of labor with use of a foley catheter and extra-amniotic corticosteroids. Am. J. Obstet. Gynecol., 177(5): $1145-1148$

16. Kashanian M and Naghghash S (2009): Evaluation of the effect of extra- amniotic saline infusion alone or in combination of dexamethasone for induction of labor. Int. J. Gyn. Obs., 107(2):393-396.

17. Word RA, Li XH, Hnat M, et al. (2007): Dynamics of cervical remodeling during pregnancy and parturition: mechanisms and current concepts. Semin. Repord. Med., 25(1): 69-75. 